Actualité internationale de la littérature critique sur l'art contemporain

39 | Printemps 2012

CRITIQUE D'ART 39

\title{
Hugues Reip
}

\section{Julie Portier}

\section{OpenEdition \\ Journals}

Édition électronique

URL : http://journals.openedition.org/critiquedart/2641

DOI : $10.4000 /$ critiquedart.2641

ISBN : 2265-9404

ISSN : 2265-9404

Éditeur

Groupement d'intérêt scientifique (GIS) Archives de la critique d'art

\section{Édition imprimée}

Date de publication : 1 avril 2012

ISBN : 1246-8258

ISSN : $1246-8258$

\section{Référence électronique}

Julie Portier, « Hugues Reip », Critique d'art [En ligne], 39 | Printemps 2012, mis en ligne le 01 avril 2013, consulté le 22 septembre 2020. URL : http://journals.openedition.org/critiquedart/2641 ; DOI : https:// doi.org/10.4000/critiquedart.2641

Ce document a été généré automatiquement le 22 septembre 2020.

Archives de la critique d'art 


\title{
Hugues Reip
}

\author{
Julie Portier
}

\section{RÉFÉRENCE}

Hugues Reip, Sète : Villa Saint-Clair ; Paris : agnès b. 2011

1 Une rétrospective au format d'un catalogue. On se plaît à y voir une esquive de l'exposition du même type, dont le cérémonial d'usage ne siérait pas au tempérament de cette œuvre qui séduit au premier plan par sa modeste légèreté. L'art d'Hugues Reip procède par apparitions discrètes, pratique l'in situ fugace, convient de sa préférence pour les formes fragiles, minces ou impalpables. D’une inépuisable spontanéité, l'empirisme voire le bricolage y fait loi. L'ouvrage recense près de deux cents œuvres renseignées par de concises notices qui suffisent à en saisir le truc. Cette chronologie en image, traverse vingt années d'un travail dont se dessine ici la cohérence dans l'exaltante diversité, où l'enthousiasme à produire de nouveaux effets s'autorise l'usage de tous les médiums à disposition. Pensée par l'artiste, l'édition s'ouvre et se referme par des fac-similés de carnets de dessins inédits, indifférente à distinguer son statut de celui du livre d'artiste. Le ferment de l'œuvre est là, sur les pages où l'imaginaire divague, où jaillissent les couleurs surnaturelles et naissent les formes hybrides, où éclosent l'herbier fantastique et le bestiaire extraterrestre, sortis de rêves d'enfants après une indigestion de livres de vulgarisation scientifique.

2 L'enchantement irrésistible de cette œuvre inclassable mettrait-il en déroute la critique qui cherche une alternative à l'objectivité dans la forme décontractée de l'entretien (Hans Ulrich Obrist, "The Unbuild Roads", p. 19-24) ou le mode fragmentaire du glossaire (Fabio Viscogliosi, «Les Mouvements du cœur », pp. 27-30) ? Le texte semble mettre à distance son autorité en affirmant la subjectivité du discours, qui n'aurait d'autre prétention que de livrer ses notes (Michel Gauthier, pp. 33-38). Le tâtonnement et la digression méthodologiques parviennent cependant à camper un paysage culturel dans lequel appréhender l'œuvre ovni. Ils pointent des affinités artistiques dans l'art des années 1990 et dressent des généalogies par excursion dans l'histoire littéraire, les 
avant-gardes, le cinéma expérimental, la magie ou les traditions du théâtre d'ombre. Comprendre de quelle histoire elle procède permettrait-il de juger la pertinence d'une œuvre qui ressuscite d'antiques artifices, et d'en pointer les ressorts critiques?

Dans son analyse de l'exposition Le Château au domaine de Chamarande (2009), Patrick Javault soupçonne la poésie de Reip de dérégler son contexte d'apparition. A l'appui de la vidéo Blow (à Buster Keaton) (1998) qui assiste à la chute clownesque d'une cimaise dans un archétype de white cube, l'auteur laisse méditer sur ce postulat: «[...] c'est l'exposition d'art contemporain, réalité vieillie, qui se trouve replacée dans une perspective d'avenir à partir des moyens du théâtre d'illusions ou du cinéma primitif " (p. 43). Plus investie est la démonstration de Michel Gauthier, qui discerne chez l'artiste "une morale esthétique, presque politique: la lanterne magique contre "l'hypercinéma" " (p. 35), en concentrant son étude sur White Spirit (2005), carrousel projetant un théâtre d'ombres. Héritant d'une longue histoire, les ombres -ce double de la modernité- administreraient un puissant antidote au spectacle (généralisé) en restaurant la possibilité d'un va-et-vient entre l'illusion et le mécanisme qui la produit, tout en laissant intact l'émerveillement : « le principe même de la magie artistique ». 